\title{
High liveborn birth weights in the Faroes: a comparison between birth weights in the Faroes and in Denmark
}

\author{
SJÚRĐUR F OLSEN' ${ }^{1}$ AND HøGNI D JOENSEN² \\ From the Collegium Domus Regiae, ${ }^{1}$ University of Copenhagen, Denmark, and Chief Medical Officer in the \\ Faroes $^{2}$
}

SUMMARY The average birth weight of 10132 liveborn infants delivered in the Faroes during the period 1969-81 was 3610 grams, which is the highest average weight reported by 33 countries from which we were able to obtain information. Comparison of live births only between the Faroes and Denmark shows a displacement between their birth weight curves of 225 grams. A less active elective delivery in the Faroes could not explain this considerable difference. When standardisation is made with respect to discrepancies in maternal age and marital status in the two populations, the difference between their average birth weights is increased by $5 \%$ and $9 \%$ respectively. A matching for maternal parity yields a difference between the averages which is $23 \%$ below the one between the total populations. Other factors must be responsible. Both environmental and genetic factors plus the possibility of the Faroes being closer to having an optimal birth weight than other countries are discussed.

The Faroe Islands are located between Norway and Iceland, and the population of about 45000 has its own language and culture. ${ }^{1}$ Summary surveys of birth weights in the Faroes showed that these were quite high compared with Scandinavian and international standards, ${ }^{2-5}$ but a more detailed analysis of this difference is not available.

The purpose of this investigation was to determine the birth weights of liveborn infants in the Faroes during the period $1969-81$ and to compare these values with those from other countries. A more detailed comparison is made between the Faroes and Denmark.

\section{Material and methods}

The material for the Faroes comprised officially recorded data of all liveborn infants born in the period 1969-81 (10 164) which were submitted by midwives. These data were then data processed and stored by the National Board of Health in Copenhagen, Denmark. Only a minor part of this material has been published. ${ }^{2}{ }^{4}$ The material for Denmark was obtained in part directly from the National Board of Health and in part from its official publications, ${ }^{6}$ whereas the material for the remaining 31 countries was obtained from several sources. ${ }^{4-12}$ This survey includes only data on liveborn infants. This has the advantage of eliminating confusion with respect to the very great differences between countries in setting the limit between stillbirths and spontaneous abortions. The birth weights in the Faroes and Denmark are arranged according to maternal age, marital status, and number of previous pregnancies. Statistical data on parity were not available.

The birth weight distributions are available in the form of weight groups defined by $500 \mathrm{~g}$ intervals. Two principles are in use:

$-999,1000-1499, \ldots, 4500-4999,5000-($ I-999) or $-1000,1001-1500, \ldots, 4501-5000,5001-(\mathrm{I}-1000)$.

The average $(\overline{\mathrm{x}})$ and standard deviation (SD) of a birth weight distribution comprising $\mathrm{N}$ newborn infants were calculated according to the following formulas:

$\overline{\mathbf{x}}=\frac{\sum^{\sum\left(n_{i} m_{i}\right)}}{N}$ and SD $=\sqrt{\frac{\sum_{i} \overline{\left(n_{i} m_{i}{ }^{2}\right)-\bar{x}^{2} N}}{N-1}}$ where $n_{i}$ represents the number of newborn in weight-group $i$ and $m_{i}$ represents the centre of the matching interval. $m_{i}$ may assume the values $750 \mathrm{~g}$, $1250 \mathrm{~g}, \ldots, 4750 \mathrm{~g}$ and $5250 \mathrm{~g}$, whether the distribution is arranged according to the I-999 or the I-1000 principle. 
The usual practice in both Denmark and the Faroes is to round off the birth weights on birth certificates to the nearest multiple of $50 \mathrm{~g}$. Consequently, using the above formulas, a weight distribution made up according to the I-999 principle results in an average very nearly $50 \mathrm{~g}$ higher than when the I-1000 principle is used, while the corresponding standard deviations are almost equal in the two principles. In isolated cases a correction of the averages is made by subtracting $25 \mathrm{~g}$ from (I-999) or adding $25 \mathrm{~g}$ to (I-1000) the calculated averages, but in other cases comparison is made only when birth weights are recorded according to identical principles. The rounding off practice in countries other than Denmark and the Faroes was not studied, and therefore a corresponding correction of them was not possible.

Birth weight distributions were analysed statistically by standard tests on the assumption that they have a normal distribution, which is approximately correct. The figure shows the total distribution of liveborn birth weights in the Faroes and in Denmark. The figure is plotted on probit paper where each line represents a normal distribution with a standard deviation that is proportional to the slope of the line. It can be seen that the curves below the 10 percentile and above the 95 percentile deviate from the remaining linear distributions, which represent the intervening $85 \%$ of birth weights. The level of significance is $p=0.05$.

\section{Results}

The average and standard deviation in the Faroes for the period 1969-81 representing 10132 liveborn infants was $3610 \pm 603 \mathrm{~g}$ (corrected average). During that period the annual birth weight average (corrected) fluctuated from $3585 \mathrm{~g}$ to $3643 \mathrm{~g}$, but chance alone can explain these deviations (analysis of variance: $p>0 \cdot 1$ ).

In table 1 are recorded the average birth weights and standard deviations of countries where the liveborn birth weights are the highest. Unfortunately, it was possible to obtain birth weights only according to either I-999 or I-1000 for most of the countries, making necessary the corresponding division of the table. It can be seen that the highest birth weights occurred in the Faroes, followed by Iceland and then Norway. The differences in average birth weights between the Faroes and Iceland, and between Iceland and Norway, both amount to about $50 \mathrm{~g}$ and are statistically significant (Student $t$ test: $\mathrm{p}<0.001$ ).

The figure shows a parallel displacement between the Faroese and Danish birth weight curves of $225 \mathrm{~g}$. Moreover, relatively heavier infants were born in the Faroes than in Denmark, since the curves deviate from each other above the 75 percentiles. In the same time period the frequency of newborn infants who were lighter than $2501 \mathrm{~g}$ was about 1.7 times greatero in Denmark than in the Faroes $(5.9 \% v 3 \cdot 5 \%)$, while the frequency of newborn infants heavier than $\vec{D}$ $4500 \mathrm{~g}$ was three times greater in the Faroes than in Denmark $(4.8 \% v 1.6 \%)$.

Table 2 shows that liveborn birth weights are related to maternal age (analysis of variance. $\mathrm{p}<0.001$ ) with a tendency to increase directly witho age in both the Faroes and Denmark. The age? distributions differ from each other in the two populations $\left(\chi^{2}\right.$ test: $\left.p<0.001\right)$. The age variation is greater in the Faroes, as a higher proportion of

Table 1 Countries with the highest average liveborn birth weights (The table includes the Faroes' neighbouring countries Iceland, Norway, and Great Britain)

\begin{tabular}{|c|c|c|c|c|c|}
\hline Grouping principle & Country & Year or period & Number of livebirths & $\begin{array}{l}\text { Birth weight }(g) \\
\text { (Average } \pm S D)\end{array}$ & Source \\
\hline I-999 & $\begin{array}{l}\text { Faroes } \\
\text { Iceland } \\
\text { Norway } \\
\text { Sweden } \\
\text { Denmark }\end{array}$ & $\begin{array}{l}1969-76 \\
1980-81 \\
1979 \\
1979 \\
1980\end{array}$ & $\begin{array}{r}6366 \\
9073 \\
51338 \\
95466 \\
57018\end{array}$ & $\begin{array}{l}3631 \pm 609 \\
3580 \pm 570 \\
3525 \pm 574 \\
3502 \pm 577 \\
3411 \pm 585\end{array}$ & $\begin{array}{l}- \\
* \\
8 \\
+\end{array}$ \\
\hline$I-1000$ & $\begin{array}{l}\text { Faroes } \\
\text { Iceland } \\
\text { New Zealand } \\
\text { Denmark } \\
\text { San Marino } \\
\text { Great Britain } \\
\text { England and Wales }\end{array}$ & $\begin{array}{l}1977-81 \\
1972-74 \\
1974-80 \\
1972-80 \\
1972-78 \\
1970 \\
1980-82\end{array}$ & $\begin{array}{r}3766 \\
13615 \\
278746 \\
595668 \\
1740 \\
16815 \\
1773575\end{array}$ & $\begin{array}{l}3591 \pm 593 \\
3553 \pm 593 \\
3393 \pm 576 \\
3358 \pm 580 \\
3358 \pm 564 \\
3341 \pm 628 \div, * * \\
3314 \pm 634 \div\end{array}$ & $\begin{array}{r}- \\
9 \\
4 \\
4 \\
4 \\
10 \\
11\end{array}$ \\
\hline
\end{tabular}

* Personal communication from the Director General of Public Health, Iceland.

+ Personal communication from the Medicostatistical Department, National Board of Health, Copenhagen, Denmark.

$\ddagger$ There was a slight deviation from other countries in the grouping method as the group of infants with birth weights higher than $4000 \mathrm{~g}$ was not subdivided according to the intervals $4001-4500,4501-5000$, and $5001-\mathrm{g}$. The "centre" of the interval used for calculation of that group was $4750 \mathrm{~g}$.

** Singletons only. 
Table 2 Birth weight and distribution of births according to maternal age in the Faroes and Denmark: difference between the two populations' average birth weights according to maternal age

\begin{tabular}{|c|c|c|c|c|c|c|c|}
\hline \multirow[b]{2}{*}{ Maternal age (yr) } & \multicolumn{3}{|c|}{ Faroes $1977-80(1-1000)$} & \multicolumn{3}{|c|}{ Denmark $1977(I-1000)$} & \multirow[b]{2}{*}{$D$} \\
\hline & $\boldsymbol{A}$ & $B$ & $C$ & $A$ & $B$ & $C$ & \\
\hline$\leqslant 19$ & $3454 \pm 561$ & 415 & 138 & $3240 \pm 577$ & 3960 & 64 & $214 \pm 29 \cdot 0$ \\
\hline $20-24$ & $3538 \pm 567$ & 930 & 309 & $3305 \pm 559$ & 20970 & 339 & $233 \pm 19 \cdot 0$ \\
\hline $25-29$ & $3645 \pm 570$ & 899 & 298 & $3386 \pm 572$ & 22634 & 366 & $259 \pm 19 \cdot 4$ \\
\hline $30-34$ & $3680 \pm 629$ & 478 & 159 & $3416 \pm 589$ & 11257 & 182 & $264 \pm 29 \cdot 3$ \\
\hline$\geqslant 35$ & $3644 \pm 695$ & 291 & 97 & $3425 \pm 623$ & 3011 & 49 & $219 \pm 42 \cdot 3$ \\
\hline Total & $3590 \pm 593$ & 3013 & 1001 & $3357 \pm 576$ & 61832 & 1000 & $234 \pm 11 \cdot 1$ \\
\hline
\end{tabular}

$A=$ birth weight: $\tilde{\mathbf{x}} \pm$ SD.

$\mathrm{B}=$ number of births: $\mathbf{n}$.

$C=$ rate per 1000 births.

$\mathrm{D}=$ difference between average birth weights of the Faroes and Denmark \pm standard error of the difference:

$$
\overline{\mathbf{x}}_{\mathrm{F}}-\overline{\mathbf{x}}_{\mathrm{DK}} \pm \sqrt{\frac{S D_{F}^{2}}{n_{F}}+\frac{S D_{D K}^{2}}{n_{D K}}}
$$

women who have babies before 20 and after 34 is seen there. When standardisation for this discrepancy is made by transferring the Danish age distribution to the Faroes, an increase in the Faroese birth weight to $3602 \mathrm{~g}$ occurs, corresponding to an increase in the difference between the two countries' average birth weights by $5 \%(246 \mathrm{~g} v 234 \mathrm{~g})$. The difference fluctuated from $214 \mathrm{~g}$ to $264 \mathrm{~g}$ in the various age groups, but chance alone can explain this variation (analysis of variance: $p>0 \cdot 1$ ).

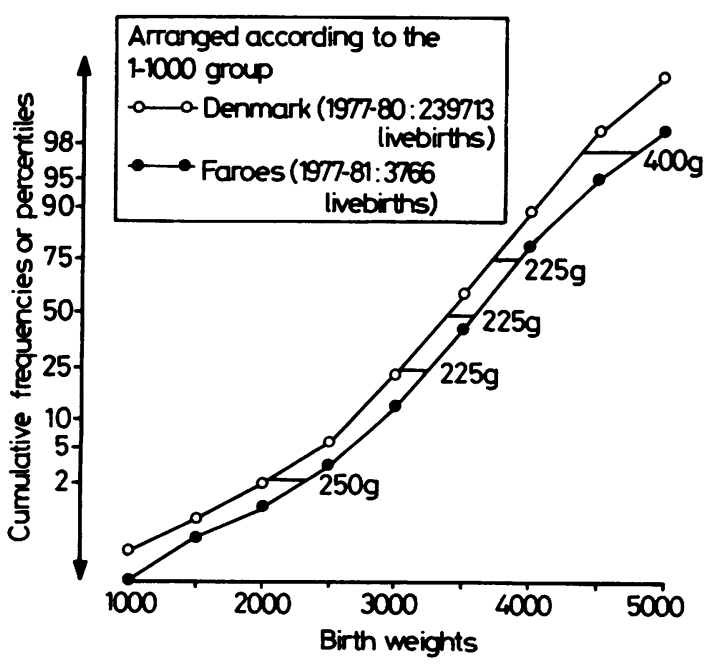

Cumulated frequencies of liveborn birth weights in the Faroes and in Denmark. The values are plotted on probit paper, see Material and methods. The differences between the curves at the 2, 25, 50,75, and 98 percentiles are shown.
Table 3 shows that birth weights in both populations are lower in infants born to unwed mothers, widows, and divorced women than in infants born to married or separated women (Student $t$ test: $\mathrm{p}<0.001)$. The births are distributed differently according to these two groups in the Faroes and in Denmark ( $\chi^{2}$ test: $\left.p<0.001\right)$. A higher proportion of women who have babies outside marriage is seen in the Faroes. When standardisation for this discrepancy is made by transferring the distribution of Danish births according to maternal marital status to the Faroes, the difference between the birth weights in the two countries is increased by $9 \%(247 \mathrm{~g} v 226 \mathrm{~g})$. The difference between the populations' average birth weights is larger in married and separated women than in the remainder $(256 \mathrm{~g} v 190 \mathrm{~g})$ (Student $t$ test: $\mathrm{p}<0.005)$.

Table 4 shows that birth weights of liveborn infants in both populations are related to the number of previous pregnancies (analysis of variance: $\mathrm{p}<0.001$ ), with a tendency to rise directly with the number in the Faroes but not in Denmark. The populations' composition with respect to this factor differs in the two countries $\left(\chi^{2}\right.$ test: $\left.p<0 \cdot 001\right)$. Standardisation for this discrepancy by transferring the Danish maternal distribution to the Faroes reduces the difference between the two populations' average birth weights by about $9 \%(215 \mathrm{~g} v 235 \mathrm{~g})$. The difference between the birth weights is related to the number of maternal previous pregnancies (analysis of variance: $p<0.001$ ) with a tendency to increase directly with the number. The difference is $23 \%$ lower in the group "zero previous pregnancies" than in the total population (182 $\mathrm{g} v 235 \mathrm{~g})$.

\section{Discussion}

Birth weights of liveborn infants in the Faroes are the highest in 33 countries from which we were able to 
Table 3 Birth weight and distribution of births according to maternal marital status in the Faroes and Denmark: difference between the two populations' average birth weights according to maternal marital status

\begin{tabular}{|c|c|c|c|c|c|c|c|}
\hline \multirow{2}{*}{$\begin{array}{l}\text { Maternal marital } \\
\text { status }\end{array}$} & \multicolumn{3}{|c|}{ Faroes 1971-76 (I-999) } & \multicolumn{3}{|c|}{ Denmark $1972(I-999)$} & \multirow[b]{2}{*}{$D$} \\
\hline & $A$ & $B$ & $C$ & $\boldsymbol{A}$ & B & C & \\
\hline $\begin{array}{l}\text { Unmarried, widowed, } \\
\text { or divorced } \\
\text { Married or }\end{array}$ & $3483 \pm 614$ & 1168 & 249 & $3293 \pm 601$ & 10877 & 144 & $190 \pm 18 \cdot 8$ \\
\hline separated & $3688 \pm 595$ & 3541 & 752 & $3432 \pm 577$ & 64619 & 856 & $256 \pm 10 \cdot 3$ \\
\hline Total & $3637 \pm 606$ & 4709 & 1001 & $3411 \pm 583$ & 75496 & 1000 & $226 \pm 9.08$ \\
\hline
\end{tabular}

$A=$ birth weight: $\overline{\mathbf{x}} \pm \mathrm{SD}$.

$\mathbf{B}=$ number of births: $\mathbf{n}$.

$C=$ rate per 1000 births.

$\mathrm{D}=$ difference between average birth weights of the Faroes and Denmark \pm standard error of the difference:

$$
\bar{x}_{F}-\bar{x}_{D K} \pm \sqrt{\frac{S D_{F}^{2}}{n_{F}}+\frac{S D_{D K}^{2}}{n_{D K}}}
$$

obtain information, and they have remained at a constant level during the 13-year period. In order to determine the reason for these high birth weights, a comparison was made of the Faroes and Denmark. These two countries are well suited for comparison because (1) the maternal experts in the Faroes (midwives and doctors) are nearly all trained in Denmark, and therefore the procedures and terminology are very similar; (2) the same legal obligations concerning reporting child birth data are present in both countries, and these data are computed in the same place (National Board of Health, Copenhagen); (3) the two countries' health and social standards are highly comparable.

For the most part the observed difference in average birth weights in the two countries of about $230 \mathrm{~g}$ reflects a displacement of about $225 \mathrm{~g}$ in all the weight groups. The percentage of medically induced deliveries during $1977-81$ in the Faroes was $19 \%,{ }^{13}$ while in Denmark it was $10 \%$ in $1979 .{ }^{14}$ This, together with the finding of a displacement of all weight groups, makes the possibility of a less active elective delivery in the Faroes as a cause for the discrepancy between the two birth weight averages very improbable.

Birth weight is known to increase with increasing 0 maternal age and parity when examined separately, $\vec{O} \dot{\sim}$ and it tends to be higher in children born of mothers? who are married than in others. ${ }^{1015}$ Statistics on $\Phi^{\rightarrow}$ parity were not obtainable but the number of previous pregnancies may reflect the same major trends, and therefore this factor was investigated (at) the time of the study, legislation concerning induction of abortion was identical and conservative in both countries).

There is a relationship between the greater variation in maternal age in the Faroes and a higher total fertility rate (total number of liveborn children per 1000 women): during $1976-80$ it was 2635 in the Faroes and 1645 in Denmark. ${ }^{20}$ These phenomena

Table 4 Birth weight and distribution of births according to number of previous maternal pregnancies in the Faroes and Denmark: difference between the two populations' average birth weights according to number of previous maternal pregnancies

\begin{tabular}{|c|c|c|c|c|c|c|c|}
\hline \multirow{2}{*}{$\begin{array}{l}\text { No of previous } \\
\text { maternal pregnancies }\end{array}$} & \multicolumn{3}{|c|}{ Faroes 1970-76 (I-999) } & \multicolumn{3}{|c|}{ Denmark 1972 (I-999) } & \multirow[b]{2}{*}{$D$} \\
\hline & $\boldsymbol{A}$ & $B$ & $C$ & $\boldsymbol{A}$ & $B$ & $C$ & \\
\hline 0 & $3509 \pm 589$ & 1713 & 310 & $3327 \pm 566$ & 26144 & 369 & $182 \pm 14 \cdot 6$ \\
\hline 1 & $3634 \pm 591$ & 1486 & 269 & $3437 \pm 592$ & 24100 & 340 & $197 \pm 15.8$ \\
\hline 2 & $3715 \pm 585$ & 1114 & 202 & $3452 \pm 595$ & 12114 & 171 & $263 \pm 16 \cdot 6$ \\
\hline 3 & $3724 \pm 574$ & 635 & 115 & $3440 \pm 627$ & 4920 & 70 & $284 \pm 24 \cdot 5$ \\
\hline 4 & $3867 \pm 644$ & 278 & 50 & $3408 \pm 658$ & 2019 & 29 & $459 \pm 41 \cdot 3$ \\
\hline 5 or more & $3755 \pm 651$ & 292 & 53 & $3394 \pm 714$ & 1494 & 22 & $361 \pm 42 \cdot 3$ \\
\hline Total & $3635 \pm 609$ & 5518 & 999 & $3399 \pm 588$ & 70791 & 999 & $235 \pm 8 \cdot 5$ \\
\hline
\end{tabular}

$A$ = birth weight: $\overline{\mathbf{x}} \pm \mathrm{SD}$.

$\mathbf{B}=$ number of births: $\mathbf{n}$.

$C=$ rate per 1000 births.

$D=$ difference between average birth weights of the Faroes and Denmark \pm standard error of the difference:

$$
\bar{x}_{F}-\bar{x}_{D K} \pm \sqrt{\frac{S D_{F}^{2}}{n_{F}}+\frac{S D_{D K}^{2}}{n_{D K}}}
$$


and the occurrence of a higher proportion of women who have babies outside marriage in the Faroes may be explained by differences in the two populations with respect to the following conditions: (1) general attitudes towards (a) the age at which women should have babies; (b) the size of the family; and (c) having an abortion; (2) availability of contraceptives; (3) legislation concerning induction of abortion. As mentioned above, the indications in the laws were identical in both countries until April 1970, when a liberalisation was made in Denmark; in October 1973 free abortion was legalised in Denmark, whereas in the Faroes no change has been made since 1959; thus legislation has been more liberal in Denmark during both periods in question (see tables 2 and 3).

When standardisation of the two populations is made with respect to maternal age, marital status, and number of previous pregnancies, the difference between the populations' average birth weights is increased by $5 \%$ and $9 \%$ in the first two parameters and decreased by $9 \%$ in the last. In the group of "zero previous pregnancies" the mothers match each other directly with respect to parity. The difference between the populations' average birth weights of the infants of those mothers who had had no abortions or previous childbirths is $23 \%$ lower than the difference between the values of the total populations.

Neither differences between the practice of inducing deliveries nor differing maternal distributions according to age, marital status, and parity can thus satisfactorily explain the considerable difference in the average liveborn birth weights in the two populations.

The prevalence of insulin-requiring diabetes mellitus in the Faroes is about half that in Denmark. ${ }^{16}$

Environmental determinants of birth weight may occur differently in the Faroes, where fishing and the fishing industry are predominant occupations, and in more industrialised and urbanised Denmark. Maternal smoking of more than 15 cigarettes a day has been found to reduce the average birth weight by $158 \mathrm{~g},{ }^{17}$ but it seems to us very unlikely that there should be such a large difference between the smoking habits of pregnant women in the two populations. The difference between the two populations' average birth weights was larger for infants born to married and separated women than to others. Possible differences in the occurrence of environmental determinants may therefore manifest themselves more strongly in that group. The difference between the birth weights was found to be unrelated to maternal age. Its relationship to earlier maternal pregnancies is difficult to interpret, as indicated above.
Anthropological studies have shown a large number of common characteristics between the Faroese and the Icelandic people. ${ }^{18}{ }^{19}$ The extremely high birth weights here compared to those in the rest of the world can possibly be related to a common ethnic background. However, these countries presumably also have a large number of common environmental and social characteristics (fishing industry, habits of life, nourishment, etc).

The late fetal death rate per 1000 livebirths in $1976-80$ in the Faroes was $11 \cdot 0$, whereas it was $5 \cdot 6$ in Denmark. ${ }^{20}$ The difference between these two values is anyway too small to account for the observed discrepancy between the birth weights of liveborn infants through a stronger selection of heavy infants in the Faroes.

Generally there is an inverse relationship between the proportion of heavy infants in a country and its infant mortality rate..$^{5}$ The higher frequency of stillbirths in the Faroes than in Denmark is thus probably caused by factors unrelated to birth weight. Indeed, if the high birth weight in the Faroes is environmentally determined, it may be that this population is closer to the optimal birth weight than others.

Additional epidemiological studies are necessary to explain these conditions. Causes of perinatal mortality plus the degree and type of employment, smoking, and eating habits during pregnancy must be investigated. In their isolated location the Faroes offer a relatively well defined population and therefore present a highly suitable location for epidemiological studies.

We express our gratitude to the National Board of Health in Copenhagen for kindly making available to us data on the material from the Faroes. We are especially grateful to Olaf Bonnevie, chief physician, $\mathrm{dr}$ med, for help in solving problems of an epidemiological character. We thank Lisbeth B Knudsen, mag scient soc (National Board of Health), Dyre Trolle, professor in obstetrics, and Thorkild I A Sørensen, dr med, for reading and discussing the manuscript. Arne Nielsen, lic act, is also thanked for helpful assistance with the statistics. Bjarni Olsen, cand scient oecon, helped to compute the data.

Correspondence and reprint requests to: Sjúrður F Olsen, Registrar, Landssjúkrahúsið, 3800 Tórshavn, Faroe Islands, Denmark. 


\section{References}

${ }^{1}$ West JF. Faroes, the emergence of a nation. London: C Hurst, 1972.

${ }^{2}$ Joensen HD. Annual Report 1982. Tórshavn: The Chief Medical Officer in the Faroes, 1983.

${ }^{3}$ United Nations Association. United Nations Demographic Yearbook 1975. New York: UN, 1976; 753.

4 United Nations Association. United Nations Demographic Yearbook 1981. New York: UN, 1983; 811-5.

${ }^{5}$ Saugstad LF. Weight of all births and infant mortality. $J$ Epidemiology Community Health, 1981; 35: 185-91.

${ }^{6}$ Sundhedsstyrelsen. Medicinsk Fødselsstatistik, 1970. Medicinalstatistiske meddelelser, 1973; 1 .

${ }^{7}$ Sundhedsstyrelsen. Medicinsk Fødselsstatistik, 1977. Medicinalstatistiske meddelelser, 1979; 1 .

${ }^{8}$ NOMESKO. Births in the Nordic countries. Registration of the outcome of pregnancy 1979. Reykjavík, 1982.

${ }^{9}$ Snædal G, Biering G, Sigvaldason H. Obstetrics and perinatal medicine in Iceland 1881-1971. With a detailed report on deliveries in Iceland 1972-74. Acta Obstet Gynecol Scand, Supplement 45, 1975.

${ }^{10}$ Chamberlain R, Chamberlain G, Howlett B, Claireax A. British births 1970, vol. 1. London: Heineman Medical, 1975.
${ }^{11}$ Office of Population Censuses \& Surveys. Birthweight statistics 1980 \& Birthweight statistics 1981, 1982 (England and Wales). London: (Publications of the Government Statistical Service), 1981, 1982.

${ }^{12}$ Jørgensen P, Møller J, Zachau-Christiansen B. Live born in Greenland, birth weight, neonatal and infant mortality during 1975 to 1979. Nordic Council for Arctic Medical Research Report No. 33, 1981; 166-8.

${ }^{13}$ Joensen HD. Annual Reports 1980 \& 1981. Tórshavn: The Chief Medical Officer in the Faroes, 1981, 1982.

${ }^{14}$ Sundhedsstyrelsen. Medicinsk Fødselsstatistik, 1979. Vitalstatistik 1982; 1: 1 .

${ }^{15}$ Selvin S, Jenerich DT. Four factors influencing birth weight. Br J Prev Soc Med, 1971; 25: 12-6.

${ }^{16}$ Simonsen HJ, Madsen H, Róin J, Green A, Hauge M, Holm N. Diabetes mellitus in the Faroese population. An epidemiological study. Nordic Council for Arctic Medical Research Report No. 33, 1981; 310-2.

${ }^{17}$ Dougherty CRS, Jones AD. The determinants of birth weight. Am J Obstet Gynecol, 1982; 144: 190-200.

${ }^{18}$ Olsen Á. Blódflokkar í Føroyum (Bloodgroups in the Faroes). Varôin, 1951; 29: 190-7. Tórshavn.

${ }^{19}$ Harvey RG, Tills D, Warlow A, Suter D. Anthropological studies in the Faroe Islands. Nordic Council for Arctic Medical Research Report No. 26, 1980; 7-11.

${ }^{20}$ Nordic Statistical Secretariat. Yearbook of Nordic statistics 1982. Stockholm, 1983. 